\title{
Postprandial Insulin and Glucagon Secretions during a Mixed-Meal Tolerance Test in Dietary Induced Metabolic Syndrome Cynomolgus Monkeys
}

Changqing Zhang ${ }^{1^{*}}$, Li Zhang ${ }^{2}$, Shanshan Ding ${ }^{1}$, Yupeng Fang ${ }^{1}$, Alexander Hovard Sparre-Ulrich ${ }^{3}$, Mikkel Christensen ${ }^{4,5}$, Shanhai Zong ${ }^{6}$, Qian Ma $^{6}$, Shoutao Liu $^{1}$, Joyce Hwa ${ }^{2}$ and Xin Zhang

${ }^{1}$ DMPK Services Department, Lab Testing Division, WuXi Apptec Co., Ltd, Suzhou, Jiangsu Province, China

${ }^{2}$ DMPK Services Department, Lab Testing Division, WuXi Apptec Co., Ltd, New Jersey, USA

${ }^{3}$ Antag Therapeutics ApS, Copenhagen, Denmark

${ }^{4}$ Department of Clinical Pharmacology, Copenhagen University Hospital Bispebjerg and Frederiksberg, Copenhagen, Denmark

${ }^{5}$ Clinical Metabolic Physiology, Steno Diabetes Center Copenhagen (SDCC), Hellerup, Denmark

${ }^{6}$ Large Molecular Bioanalysis Department, Lab Testing Division, WuXi Apptec Co., Ltd, Suzhou, China

${ }^{7}$ DMPK Services Department, Lab Testing Division, WuXi Apptec Co., Ltd, Shanghai, China

"Corresponding author: Changqing Zhang, DMPK Services Department, Lab Testing Division, WuXi Apptec Co., Ltd, Suzhou, Jiangsu Province, China, Tel: +8618061921926; E-mail: changqing321@126.com (or) zhang_changqing@wuxiapptec.com

Received date: June 27, 2018; Accepted date: July 11, 2018; Published date: July 13, 2018

Copyright: $\odot 2018$ Zhang C, et al. This is an open-access article distributed under the terms of the Creative Commons Attribution License, which permits unrestricted use, distribution, and reproduction in any medium, provided the original author and source are credited.

\begin{abstract}
Objective: The objective of this investigation was to assess the postprandial glucose, insulin and glucagon responses to a mixed-meal tolerance test (MMTT) in Cynomolgus monkeys with dietary-induced obese, prediabetes or overt type-2 diabetes mellitus (T2DM) and compare them to chow-fed controls.

Method: Mixed meal was administered via nasogastric gavage in eighteen adult male Cynomolgus monkeys stratified into four groups - either T2DM $(n=3)$, pre-diabetes $(n=5)$, metabolically healthy obese $(n=5)$ or chow-fed control $(n=5)$. The plasma was sampled for fasting and postprandial glucose, insulin and glucagon concentrations. And based on these, we calculated areas under curves (AUCs) of postprandial glucose, insulin and glucagon. Homeostasis model assessment-estimated insulin resistance (HOMA-IR) and insulinogenic Index (IGI) were used to estimate pancreatic secretion and insulin resistance.
\end{abstract}

Results: Compared to control group, the T2DM, pre-diabetes and obese groups had higher plasma fasting glucose and insulin concentrations, and a greater postprandial glucose and insulin AUC $0240 \mathrm{~min}$. The HOMA-IR and IGI indicated that the obese, pre-diabetes and T2DM animals are more insulin resistant and have impaired beta cell function compared to animals in control group. The highest and lowest fasting plasma glucagon concentrations were found in the pre-diabetes and T2DM groups, respectively and both groups showed moderate postprandial glucagon $\mathrm{AUC}_{0-240 \mathrm{~min}}$. Mild fasting plasma glucagon but a greatest postprandial glucagon $\mathrm{AUC}_{0-240}$ min was found in obese group. Moderate fasting plasma glucagon and a smallest postprandial glucagon $A \cup C_{0240}$ min were found in the control group.

Conclusion: The results of postprandial insulin and glucagon secretions in responses to the postprandial glucose challenge enclosed with anthropometric and lipidemic parameters well demonstrated the insulin sensitivity with beta and alpha cells function in each classified group and the very similar patterns to humans. It revealed that dietary induced metabolic disorders in Cynomolgus monkeys are useful models to study the therapeutically agents for human metabolic syndrome and T2DM.

Keywords: NHP; Type 2 diabetes; Insulin resistance; Obesity; Glucagon; Insulin

\section{Abbreviations}

MMTT: Mixed-meal tolerance test; MS: Metabolic syndrome; HbA1C: Hemoglobin A1C; IVGTT: Intravenous glucose tolerance test; OGTT: Oral glucose tolerance test; IACUC: Institutional animal care and use committee; T2DM: Type 2 diabetes; AUC: Areas under curve; IGI: Insulinogenic index; TC: Total cholesterol; HDL-C: High density lipoprotein-cholesterol; LDL-C: Low density lipoprotein-cholesterol; TG: Total triglyceride; FFA: Free fat acid.

\section{Introduction}

Insulin and glucagon are the primary gluco-regulatory hormones; regulate the levels of blood glucose in our body. The two hormones work in balance to maintaining the euglycemia level in normal physiological conditions.

Insulin is produced from beta islet cells of pancreas. As an anabolic hormone, in response to postprandial glucose removal from circulating 
Citation: Zhang C, Zhang L, Ding S, Fang Y, Sparre-Ulrich AH, et al. (2018) Postprandial Insulin and Glucagon Secretions during a Mixed-Meal Tolerance Test in Dietary Induced Metabolic Syndrome Cynomolgus Monkeys. J Vet Sci Technol 9: 550. doi: $10.4172 / 2157-7579.1000550$

Page 2 of 7

by signaling the highly insulin - responsive peripheral tissues such as skeletal muscle, adipose, and liver to increasing glucose uptake, and triglyceride storage and promoting of glycogenesis in liver while also suppresses the glucose production and inhibiting the suppress of glucagon secretion [1].

With an opposite function of insulin, glucagon is produced from alpha islet cells and its secretion is complex. Involving the combination of paracrine, autocrine hormonal as well as autonomic neural mechanisms [2]. However, in addition to glucose and insulin, glucagon secretion is regulated by gut incretin hormones of glucagon-like peptide 1 (GLP-1) and glucose dependent insulunotropic polypeptide (GIP) [3]. As a catabolic hormone, glucagon acts in response to raising and maintaining circulating glucose level to meet physiological needs during the fasting state, or the hypoglycemia condition mainly through the hepatic glucose production [1]. Both hormones play a vital role in regulating blood glucose levels, and if the level of one hormone is outside the ideal range, blood sugar levels may elevate or drop.

Imbalanced blood glucose levels related to genetic insulin hormone defect and the insulin resistance with further overt type 2 diabetes. It has also been well recognized that overtime of excessive intake and physical inactivity causes obesity that consequent hyperglycemia, metabolic syndrome, insulin resistance (pre-diabetes) and then type 2 diabetes.

In early of pre-diabetes pathological process, insulin secretion has initially increased in beta cell function compensatory way to facilitate entry of excess blood glucose to peripheral tissues and liver for utilization of energy and storage via glycogenesis. But over time of insulin compensatory secretion causes the exhausting of beta cell function, the beta cell postprandial action becomes abnormal, as evidenced by the loss of immediate insulin response to a meal $[1,4]$. The elevated levels of fasting glucose and insulin, along with an impaired glucose tolerance test are well defined as pre-diabetes, and also defined as the insulin resistance syndrome $[1,3]$.

If any of food intake restriction and physical activity are still missing in the pre-diabetes stage, the T2DM is essentially developed from worsening hyperglycemia comes with the significantly increased fasting glucose and $\mathrm{AlC}$ value with peripheral insulin resistance coupled with progressive beta cell dysfunction.

Besides of insulin, people with T2DM have defects in both insulin and glucagon secretion [5-7]. It is also known that type-2 diabetes is associated with elevated levels of glucagon [4,8-10] and defective suppression of glucagon secretion. Moreover, it also had a numerous study described that glucagon suppression is impaired after an oral or intravenous glucose load in pre-diabetes and T2DM [11-18] the increased alpha-cell function in pre-diabetes and T2DM consequent hyper glucagonemia by stimulating hepatic glucose production $[4,19]$ As the regulators to glucagon secretion, the glucagon-like peptides 1 (GLP-1) and glucose-dependent insulinotropic polypeptide (GIP) are most important ones to consider when studying glucagon secretion in vivo $[4,16,17]$.

It has been reported that glucose-induced insulin response is greater after an oral load as compared with an IV glucose injection because of the effect of incretins [20]. So a standard mixed meal tolerance test (MMTT) corresponding to a standardized oral glucose tolerance test (OGTT) may yield a more physiological and suitable model to test the impact of insulin and glucagon on postprandial glucose regulation [21]. But a major limitation to the study of the MS in humans, and especially the pathogenesis of these disorders and their related metabolic abnormalities, is the lack of appropriate animal models with which to rigorously investigate the progression and biological mechanisms of the disease processes. Currently, more studies related to obesity/diabetes research are moving toward using nonhuman primates (NHPs) which have better pathophysiological metabolism similarities to humans [22,23]. Many characteristics of the Cynomolgus monkey (Macaca fascicularis) make the species ideal for this purpose $[24,25]$. But the report of postprandial relationship between glucagon, insulin and glucose in Cynomolgus monkeys is scarce.

In this investigation, we aimed to characterize the glucose, insulin and glucagon responses and indices of insulin resistance during a MMTT in a high fat and high fructose diet-induced Cynomolgus metabolic model of obese pre-diabetes, and overt T2DM in comparison to control.

\section{Materials and Methods}

Thirteen monkeys were fed a high-calorie (high fat diet \& high fructose) diet to induce the metabolic syndrome diseases models. Five monkeys were fed normal monkey diet and with normal intravenous glucose tolerance test (IVGTT) profile served as age-matched chowfed controls. The high-calorie fed animals developed varying metabolical alterations and all animals could be stratified into groups of metabolically healthy obese, pre-diabetes, T2DM, and controls according to their hemoglobin $\mathrm{A} 1 \mathrm{C} \%(\mathrm{HbA1C} \%)$ values and glycemic status defined from plasma glucose level at 60 minutes in an IVGTT. The detail criteria for stratify animals were report previously [26].

All animals were obtained from an approved vendor (Hainan Jingang Biotechnology, Hainan, China), and housed in a controlled animal facility with a 12:12-h light:dark cycle; reverse-osmosispurified water was available without restriction to all animals. Enrichment toys and treats were provided on a daily basis.

All eighteen Cynomolgus macaques underwent a MMTT via nasogastric gavage administration. The MMTT procedure in Cynomolgus macaques was conducted as approved by the IACUC of WuXi Apptec (Suzhou, Jiangsu Province, People's Republic of China), which is in compliance with the Animal Welfare Act and guidelines in the Guide for the Care and Use of Laboratory Animals.

Animals were trained for oral gavage administration prior to the test. The MMTT was performed in the morning of the test day under slight sedation with ketamine, after about 14 hours overnight fast. And following the baseline sampling ( $-30,-5$ minutes) the animals have received a test meal via the gavage administration. Ensure plus ${ }^{\oplus}$ was purchased from Abbott company, and used as the test meal in this MMTT. A single dose of Ensure plus ${ }^{\oplus}(350 \mathrm{Kcal}, 17 \%$ carbohydrate, $17 \%$ fat, and $26 \%$ protein) to each monkey is calculated by $6 \mathrm{~mL}$ per kilogram of body weight multiple the individual body weight. Postprandial sampling for glucose, insulin and glucagon assessments collected at $15,30,45,60,90,120,180,240$ minutes after gavage administration.

Blood chemistries of total cholesterol, triglyceride and liver enzymes were determined by using Biochemical analyzer (HITACHI 7180). Glucose was measured by glucose oxidase method, using a Glucose analyzer (EKF Biosen C-line). Insulin ELISA kits (Catalog no.: 10-1113-01 \& 10-1113-10) and glucagon ELISA kits (Catalog no: 10-1271-01) were purchased from Mercodia Developing Diagnostics. 
Citation: Zhang C, Zhang L, Ding S, Fang Y, Sparre-Ulrich AH, et al. (2018) Postprandial Insulin and Glucagon Secretions during a Mixed-Meal Tolerance Test in Dietary Induced Metabolic Syndrome Cynomolgus Monkeys. J Vet Sci Technol 9: 550. doi: $10.4172 / 2157-7579.1000550$

Page 3 of 7

Hemoglobin Alc (HbAlc) was determined by using DCA Vantage analyzer (Siemens). Total body fat composition was determined by using Dual Energy X-ray bone density machine (HOLOGIC Discovery A).

\section{Statistical analysis and calculations}

All results are expressed as mean \pm SEM (except HOMA-IR \& IGI were expressed as mean). AUC value was calculated by using Phoenix WinNonlin software (version 6.2.1, Pharsight, Mountain View, CA), the non-compartmental model (Linear/log trapezoidal, best fit) was used.

Differences between groups and within groups were evaluated using one-way ANOVA followed by Tukey's multiple comparison post tests using Graph Pad statistic software. A p value of less than 0.05 is considered statistically significant.

The insulinogenic index (IGI), as a surrogate marker of beta cell function has largely used in human clinical trials to estimate the level of insulin secretion with a more physiological route of glucose administration and evaluate subjects in different metabolic status. It measured of first-phase insulin response to glucose challenge during the first 30 minutes of the OGTT or MMTT and is computed by following the equation as $\mathrm{IGI}=\delta$ insulin $(0-30 \mathrm{~min}) / \delta$ glucose $(0-30$ $\mathrm{min}$ ) Insulin is measured in micro units per milliliter, whereas glucose is measured in milligrams per deciliter [27].

The HOMA-IR is also a useful method have been used with numbers of human epidemiological studies in quantifying the degree of insulin resistance and beta cell function in human subjects among ethnic groups, as well in comparison of HOMA-IR and beta cell function between or within groups. The equation known as HOMA$\mathrm{IR}=($ fasting insulin concentration $\times$ fasting glucose concentration $) /$ 22.5 , calculations are based on $\mathrm{mmol} / \mathrm{L}$ for glucose and $\mathrm{mU} / \mathrm{mL}$ for insulin [28].

\section{Results}

\section{The anthropometries and measured lipid parameters}

Anthropometric characteristics and lipids parameters of 18 monkeys in T2DM, pre-diabetes, obese and control groups are presented as Mean \pm SEM in Table 1 .

\begin{tabular}{|c|c|c|c|c|}
\hline Group & T2DM & $\begin{array}{l}\text { Pre } \\
\text { diabetes }\end{array}$ & Obese & Control \\
\hline Age (Year) & $\begin{array}{ll}14.3 & \pm \\
0.33 & \end{array}$ & $\begin{array}{ll}14.4 & \pm \\
0.40 & \end{array}$ & $\begin{array}{ll}14.0 & \pm \\
0.00\end{array}$ & $\begin{array}{ll}12.8 & \pm \\
1.28 & \end{array}$ \\
\hline Body Weight (kg) & $\begin{array}{ll}10.5 & \pm \\
2.01 & \end{array}$ & $\begin{array}{ll}9.47 & \pm \\
0.76 & \end{array}$ & $\begin{array}{ll}10.1 & \pm \\
0.63 & \end{array}$ & $\begin{array}{l}9.02 \quad \pm \\
0.76\end{array}$ \\
\hline $\begin{array}{l}\text { Total Body Fat Composition } \\
(\%)\end{array}$ & $\begin{array}{l}46.0 \\
3.68^{\star *}\end{array}$ & $\begin{array}{l}41.1 \quad \pm \\
2.70\end{array}$ & $\begin{array}{ll}40.5 & \pm \\
1.43^{*} & \end{array}$ & $\begin{array}{l}27.7 \\
3.56\end{array}$ \\
\hline $\mathrm{HbA} 1 \mathrm{c} \%$ & 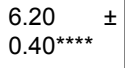 & $\begin{array}{ll}4.80 & \pm \\
0.15 & \end{array}$ & $\begin{array}{l}4.18 \\
0.09\end{array}$ & $\begin{array}{l}4.20 \quad \pm \\
0.17\end{array}$ \\
\hline $\begin{array}{l}\text { Fasting } \\
(\mathrm{mmol} / \mathrm{L})\end{array} \quad$ Plasma Glucose & $\begin{array}{ll}7.98 & \pm \\
1.27^{\star *} & \end{array}$ & $\begin{array}{ll}5.84 & \pm \\
0.328 & \end{array}$ & $\begin{array}{ll}5.26 & \pm \\
0.414 & \end{array}$ & $\begin{array}{ll}4.66 & \pm \\
0.380\end{array}$ \\
\hline Fasting Plasma Insulin (mU/L) & $\begin{array}{ll}47.3 & \pm \\
22.7 & \end{array}$ & $183 \pm 108$ & $\begin{array}{ll}44.3 & \pm \\
7.95 & \end{array}$ & $\begin{array}{l}40.7 \\
16.2\end{array}$ \\
\hline
\end{tabular}

J Vet Sci Technol, an open access journal

\begin{tabular}{|c|c|c|c|c|c|c|c|}
\hline $\begin{array}{l}\text { Fasting Plasma Glucagon } \\
(\mathrm{pmol} / \mathrm{L})\end{array}$ & $\begin{array}{ll}21.2 & \pm \\
7.33\end{array}$ & $\begin{array}{l}30.5 \\
5.84\end{array}$ & \pm & $\begin{array}{l}23.9 \\
4.55\end{array}$ & \pm & $\begin{array}{l}28.6 \\
6.48\end{array}$ & \pm \\
\hline IVGTT Glucose at Baseline & $\begin{array}{ll}4.86 & \pm \\
0.86^{*} & \end{array}$ & $\begin{array}{l}3.94 \\
0.22\end{array}$ & \pm & $\begin{array}{l}3.47 \\
0.40\end{array}$ & \pm & $\begin{array}{l}3.14 \\
0.11\end{array}$ & \pm \\
\hline IVGTT Glucose at 60 minutes & $\begin{array}{l}8.29 \\
0.40^{* *}\end{array}$ & $\begin{array}{l}5.97 \\
0.80\end{array}$ & \pm & $\begin{array}{l}4.29 \\
0.58\end{array}$ & \pm & $\begin{array}{l}3.71 \\
0.50\end{array}$ & \pm \\
\hline $\mathrm{TC}(\mathrm{mmol} / \mathrm{L})$ & $\begin{array}{l}8.26 \\
4.32\end{array}$ & $\begin{array}{l}9.15 \\
1.93\end{array}$ & \pm & $\begin{array}{l}8.50 \\
3.02\end{array}$ & \pm & $\begin{array}{l}2.91 \\
0.17\end{array}$ & \pm \\
\hline $\mathrm{TG}(\mathrm{mmol} / \mathrm{L})$ & $\begin{array}{l}0.72 \\
0.25\end{array}$ & $\begin{array}{l}1.89 \\
1.34\end{array}$ & \pm & $\begin{array}{l}0.98 \\
0.47\end{array}$ & \pm & $\begin{array}{l}0.67 \\
0.19\end{array}$ & \pm \\
\hline $\mathrm{FFA}(\mathrm{mmol} / \mathrm{L})$ & $\begin{array}{l}0.67 \\
0.09\end{array}$ & $\begin{array}{l}0.91 \\
0.15^{*}\end{array}$ & \pm & $\begin{array}{l}0.53 \\
0.08\end{array}$ & \pm & $\begin{array}{l}0.42 \\
0.11\end{array}$ & \pm \\
\hline
\end{tabular}

Table 1: Anthropometric Characteristics and Lipids Parameters. Data were presented as mean \pm SEM, T2DM, pre diabetes and obese groups were compared with control group. ${ }^{\star} \mathrm{p}<0.05,{ }^{* *} \mathrm{p}<0.01,{ }^{* * * *} \mathrm{P}<0.0001$.

The anthropometric data showed animals in T2DM, pre-diabetes and obese groups were slight older, and heavier than the animals in control group, also had a greater percentages of body fat composition than control.

The lipids parameters including total cholesterol, triglyceride and free fatty acid showed the higher levels were found in the T2DM, prediabetes and obese groups than control group animals.

\section{HbA1C\% and fasting glucose}

As glycemic parameters are also shown in Table 1, the higher $\mathrm{HbAlc} \%$ value in most groups but obese associates with higher fasting glucose and defined the impaired glucose tolerance status based on the plasma glucose level at 60 minutes from previous IVGTT.

T2DM group had a highest $\mathrm{HbA1C}$ value than others, which is statistically significant higher than control group $(\mathrm{P}<0.0001)$. T2DM group also had a highest fast plasma glucose level than others, which is statistically significant higher than control $(\mathrm{p}<0.01)$. Also, the glucose levels at baseline and 60 minutes from previously IVGTT showed the T2DM had the worsened impaired IVGTT profile.

Contrast to T2DM, the control group had the lowest $\mathrm{HbA1C}$ value and fast plasma glucose level, also associated with a normal IVGTT profile. The pre-diabetes group showed having a moderate elevated HbAlc value and fast plasma glucose level, and that is as well associated with an impaired IVGTT profile. Unlike the positively association between $\mathrm{HbA1C}$ and fast plasma glucose and IVGTT profile have found in other groups, obese group had a mild elevated fast plasma glucose level and an impaired IVGTT profile but associated with the lowest $\mathrm{HbA} 1 \mathrm{C} \%$ value similar to the control group.

\section{Postprandial plasma glucose appearances in MMTT}

The postprandial plasma glucose profile of each groups and calculated $\mathrm{AUC}_{0-240}$ min as mean \pm SEM are given in Table 2 and Figure 1 .

The glucose profiles during MMTT are different between control and groups of T2DM, pre-diabetes and obese.

Postprandial glucose levels in all groups started rising at $15 \mathrm{~min}$ after meal administration, but the time for achieving peak value are differed as earliest at 30 minutes in control compared to 45 minutes in 
Citation: Zhang C, Zhang L, Ding S, Fang Y, Sparre-Ulrich AH, et al. (2018) Postprandial Insulin and Glucagon Secretions during a Mixed-Meal Tolerance Test in Dietary Induced Metabolic Syndrome Cynomolgus Monkeys. J Vet Sci Technol 9: 550. doi: $10.4172 / 2157-7579.1000550$

Page 4 of 7

obese and pre-diabetes. Moreover, there were two peak values with the postprandial glucose appearance have found in T2DM, as the first peak occurred at $30 \mathrm{~min}$, then glucose gradually rose again after a small nadir to the second peak value at $210 \mathrm{~min}$.

\begin{tabular}{|c|c|c|c|c|c|c|c|c|c|c|}
\hline \multirow[t]{2}{*}{ Items } & \multirow[t]{2}{*}{ Group } & \multicolumn{9}{|c|}{ Time (min) } \\
\hline & & 0 & 15 & 30 & 45 & 60 & 90 & 120 & 180 & 240 \\
\hline \multirow[t]{4}{*}{ Insulin (mU/L) } & T2DM & $47.3 \pm 22.7$ & $42.7 \pm 19.5$ & $91.0 \pm 47.6$ & $102 \pm 61.8$ & $108 \pm 74.5$ & $137 \pm 80.7$ & $181 \pm 112$ & $204 \pm 125$ & $153 \pm 119$ \\
\hline & Pre diabetes & $183 \pm 108$ & $165 \pm 105$ & $232 \pm 110$ & $238 \pm 119$ & $299 \pm 169$ & $330 \pm 158$ & $254 \pm 99.0$ & $141 \pm 26.8$ & $69.7 \pm 21.6$ \\
\hline & Obese & $44.3 \pm 7.95$ & $54.4 \pm 8.28$ & $83.3 \pm 13.3$ & $90.3 \pm 26.1$ & $108 \pm 29.4$ & $88.2 \pm 21.5$ & $70.7 \pm 15.7$ & $51.4 \pm 11.8$ & $61.2 \pm 16.4$ \\
\hline & Control & $40.7 \pm 16.2$ & $65.4 \pm 14.9$ & $77.9 \pm 24.3$ & $76.7 \pm 27.9$ & $58.1 \pm 14.1$ & $35.8 \pm 10.0$ & $38.6 \pm 9.74$ & $30.3 \pm 4.25$ & $25.5 \pm 8.01$ \\
\hline \multirow[t]{4}{*}{ Glucagon (pM) } & T2DM & $21.2 \pm 7.33$ & $47.6 \pm 18.2$ & $34.2 \pm 6.55$ & $39.5 \pm 4.47$ & $27.6 \pm 4.33$ & $39.6 \pm 8.96$ & $33.9 \pm 11.4$ & $28.5 \pm 2.89$ & $20.4 \pm 1.08$ \\
\hline & Pre diabetes & $30.5 \pm 5.84$ & $59.8 \pm 23.8$ & $44.9 \pm 8.51$ & $45.8 \pm 11.3$ & $45.5 \pm 2.87$ & $42.6 \pm 7.25$ & $31.0 \pm 3.05$ & $32.7 \pm 11.0$ & $22.5 \pm 6.36$ \\
\hline & Obese & $23.9 \pm 4.55$ & $32.1 \pm 5.26$ & $30.4 \pm 7.42$ & $50.1 \pm 7.46$ & $37.3 \pm 5.19$ & $37.7 \pm 9.81$ & $26.1 \pm 7.65$ & $48.8 \pm 27.3$ & $43.6 \pm 18.7$ \\
\hline & Control & $28.6 \pm 6.48$ & $21.1 \pm 7.23$ & $19.7 \pm 6.90$ & $26.9 \pm 10.2$ & $19.0 \pm 4.23$ & $20.0 \pm 3.33$ & $19.8 \pm 2.57$ & $19.2 \pm 1.30$ & $33.4 \pm 10.3$ \\
\hline \multirow[t]{4}{*}{ Glucose (mM) } & T2DM & $7.98 \pm 1.27$ & $9.83 \pm 1.93$ & $11.1 \pm 2.54$ & $10.8 \pm 2.41$ & $10.8 \pm 1.94$ & $11.6 \pm 1.74$ & $11.9 \pm 2.40$ & $11.0 \pm 2.27$ & $7.94 \pm 1.47$ \\
\hline & Pre diabetes & $5.84 \pm 0.33$ & $9.01 \pm 1.07$ & $9.13 \pm 1.06$ & $9.64 \pm 0.87$ & $9.49 \pm 1.01$ & $9.34 \pm 1.38$ & $8.64 \pm 1.37$ & $6.60 \pm 1.44$ & $4.98 \pm 1.08$ \\
\hline & Obese & $5.26 \pm 0.41$ & $6.72 \pm 0.45$ & $6.91 \pm 0.45$ & $7.17 \pm 0.75$ & $7.01 \pm 0.64$ & $6.25 \pm 0.51$ & $6.17 \pm 0.41$ & $5.99 \pm 0.35$ & $6.21 \pm 0.62$ \\
\hline & Control & $4.66 \pm 0.38$ & $4.76 \pm 0.25$ & $5.02 \pm 0.17$ & $4.72 \pm 0.25$ & $4.73 \pm 0.35$ & $4.48 \pm 0.33$ & $4.37 \pm 0.24$ & $4.52 \pm 0.10$ & $4.33 \pm 0.22$ \\
\hline
\end{tabular}

Table 2: Postprandial Plasma Concentration of Insulin, Glucagon and Glucose. Data were presented as mean \pm SEM.
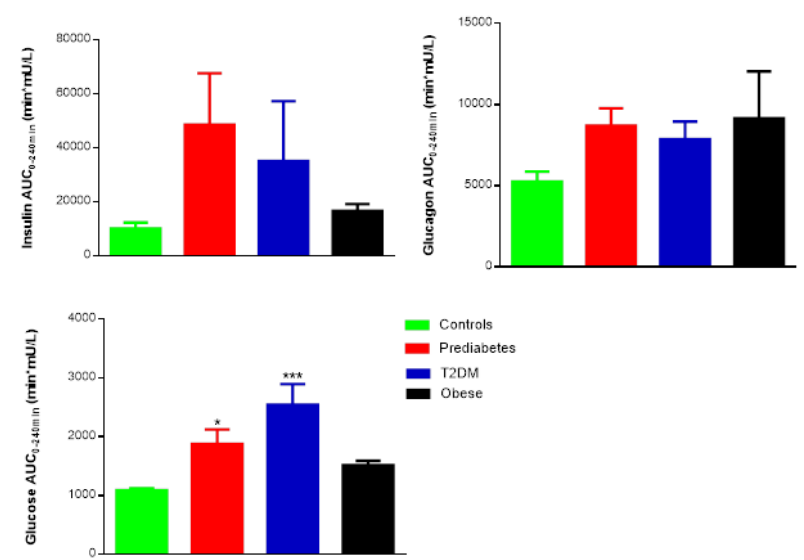

Figure 1: Area under Curve (AUC) Values from 0-240 mins Values during MMTT Data were presented as Mean \pm SEM, T2DM, pre diabetes and obese groups were compared with control group. $\mathrm{p}<0.05, \mathrm{P}<0.001$.

The times as postprandial glucose has returned to or never fall to the basal level are listed in an order from earliest to latest to never as control at 90 minutes, T2DM and pre-diabetes at 240 minutes, but obese has failed to return.

The shapes of postprandial glucose appearance in responses to MMTT resulted the different $\mathrm{AUC}_{0-240 \text { min }}$ and data showed the T2DM group had the greatest postprandial glucose $\mathrm{AUC}_{0-240 \text { min }} 2546 \pm 351$ $\mathrm{min}^{\star} \mathrm{mM}$ than other groups, followed by the pre-diabetes and obese and the control had the smallest.

\section{Postprandial insulin secretions in MMTT}

Mean \pm SEM of insulin postprandial concentrations and the calculated $\mathrm{AUCs}_{0-240}$ min during the MMTT are presented in Table 2 and Figure 1.

Overall, the postprandial insulin secretion of every group has two phases, and the patterns of secretion are different between control and groups of T2DM, pre-diabetes and obese.

The postprandial insulin enhancement in T2DM group was started at $30 \mathrm{~min}$ to a value of $91.0 \pm 47.6$ from baseline value of $47.3 \pm 22.7$ $\mathrm{mU} / \mathrm{L}$ as a small initial phase rapidly release of performed insulin, then continued up to the peak value of $204 \pm 125 \mathrm{mU} / \mathrm{L}$ at 180 minutes as second phase release of synthesized insulin to remove the remained postprandial glucose. The insulin level finally dropped to $153 \pm 119$ $\mathrm{mU} / \mathrm{L}$ at 240 minutes which resulted a moderate high insulin $\mathrm{AUC}_{0-240}$ $\min$ as $35121 \pm 22193 \mathrm{~min}^{\star} \mathrm{mU} / \mathrm{L}$ than obese and control but prediabetes groups.

The increasing of postprandial insulin secretion in pre-diabetes group is similar to T2DM, it increased to $232 \pm 110 \mathrm{mU} / \mathrm{L}$ at post-meal 30 minutes from basal level of $183 \pm 108 \mathrm{mU} / \mathrm{L}$ as a small initial phase rapidly release of performed insulin, then went up to the peak value of $330 \pm 158 \mathrm{mU} / \mathrm{L}$ at 90 minutes as second phase release of more synthesized insulin. But insulin level after which has dramatically declined to $141 \pm 26.8 \mathrm{mU} / \mathrm{L}$ at 180 minutes and ended with a significantly lower value of $69.7 \pm 21.6 \mathrm{mU} / \mathrm{L}$ to baseline level at 240 min. Moreover, postprandial insulin $\mathrm{AUC}_{0-240}$ min was calculated as $48532 \pm 19143 \mathrm{~min}^{\star} \mathrm{mU} / \mathrm{L}$, a greatest insulin AUC significantly larger $(\mathrm{P}<0.05)$ compared to rest groups of T2DM, obese and control.

In obese group, the insulin secretion has increased at 15 minutes at fed state, and faster than T2DM and pre-diabetes. It is rapidly increased to $83.3 \pm 13.3 \mathrm{mU} / \mathrm{L}$ at 30 minutes from basal $44.3 \pm 7.95$ $\mathrm{mU} / \mathrm{L}$ as a small initial phase release of performed insulin and then reached the peak value of $108 \pm 29.4 \mathrm{mU} / \mathrm{L}$ at 60 minutes as second phase for more synthesized insulin releasing. At 240 minutes, the insulin level is still at a higher value of $61.2 \pm 16.4 \mathrm{mU} / \mathrm{L}$ more than 
Citation: Zhang C, Zhang L, Ding S, Fang Y, Sparre-Ulrich AH, et al. (2018) Postprandial Insulin and Glucagon Secretions during a Mixed-Meal Tolerance Test in Dietary Induced Metabolic Syndrome Cynomolgus Monkeys. J Vet Sci Technol 9: 550. doi: $10.4172 / 2157-7579.1000550$

Page 5 of 7

baseline. The $\mathrm{AUC}_{0-240 \text { min }}$ for postprandial insulin was calculated as $16720 \pm 2458 \mathrm{~min}^{*} \mathrm{mU} / \mathrm{L}$ lower than groups of T2DM and pre-diabetes but control.

Unlike to other groups, the pattern of postprandial insulin secretion acted in age- matched control group increased immediately at post meal 15 minutes, also rapidly up to the peak value of $77.9 \pm 24.3 \mathrm{mU} / \mathrm{L}$ at 30 minutes, then gradually declined to $25.5 \pm 8.01 \mathrm{mU} / \mathrm{L}$ lower than baseline at 240 minutes. It produced a smallest $\mathrm{AUC}_{0-240 \mathrm{~min}}$ as $10141 \pm$ $2192 \mathrm{~min}^{\star} \mathrm{mU} / \mathrm{L}$ for postprandial insulin secretion than rest groups.

\section{Postprandial glucagon secretions in MMTT}

Mean \pm SEM of glucagon postprandial concentrations and the calculated $\mathrm{AUCs}_{0-240}$ min during the MMTT are presented in Table 2 and Figure 1.

The postprandial glucagon secretion increased at 15 minutes in $\mathrm{T} 2 \mathrm{DM}$, it was a 15 minutes earlier than the increasing of insulin secretion and achieved a peak value of $47.6 \pm 18.2 \mathrm{pM}$ at same time, then slowly declined to $20.4 \pm 1.08 \mathrm{pM}$, a value similar to baseline at 240 minute. The postprandial glucagon $\mathrm{AUC}_{0-240}$ min was calculated as $7863 \pm 1089$ higher than control group, but lower than pre-diabetes and obese groups.

The postprandial glucagon secretion in pre-diabetes group showed increasing from baseline and reaching to the peak value of $59.8 \pm 23.8$ pM were all occurred at 15 minutes after meal administration. The glucagon level has declined slightly to $42.6 \pm 7.25$ pM thought 90 minutes, then fallen to a value of $22.5 \pm 6.36 \mathrm{pM}$ lower than baseline at $240 \mathrm{~min}$. The postprandial glucagon $\mathrm{AUC}_{0-240 \mathrm{~min}}$ calculation resulted a greater glucagon $\mathrm{AUC}_{0-240 \mathrm{~min}}$ as $8699 \pm 1072 \mathrm{~min}^{\star} \mathrm{pM}$ higher than groups of T2DM and control but obese.

There were two peak values of postprandial glucagon secretion appeared at 45 and $180 \mathrm{~min}$ with $50.1 \pm 7.49 \mathrm{pM}$ and $48.8 \pm 27.3 \mathrm{pM}$ respectively have found in obese group during a 240 minutes MMTT. Meanwhile, obese group had a greatest $\mathrm{AUC}_{0-240 \text { min }}$ as $9155 \pm 2883$ $\min ^{\star} \mathrm{pM}$ for postprandial glucagon than control, T2DM and prediabetes groups.

The control group had a different pattern as postprandial glucagon secretion compared with other groups. While insulin secretion increasing after meal administration, the glucagon has dropped immediately from baseline value of $28.6 \pm 6.48 \mathrm{pM}$ with a flat level lower than baseline through to 180 minutes, and then increased to 33.4 $\pm 10.3 \mathrm{pM}$ at $240 \mathrm{~min}$ as insulin level has dropped significantly. The smallest $\mathrm{AUC}_{0-240 \mathrm{~min}}$ as $5270 \pm 601 \mathrm{~min}^{*} \mathrm{pM}$ for postprandial glucagon was found in control group.

\section{Assessments of IGI and HOMA -IR to monkeys in the groups of T2DM, pre-diabetes, obese and control}

IGI and HOMA-IR for the monkeys in each group using data from the MMTT and the results are shown in Table 3.

Overall the IGI numbers are shown in a rank from smallest to largest as 0.78 for T2DM, 0.82 for pre-diabetes, 1.31 for obese and 5.67 for control group. The results indicated that the control group had a largest IGI, significantly higher than other three groups and best beta cell function that also proven with the smallest postprandial glucose $\mathrm{AUC}_{0-240 \mathrm{~min}}$.

The HOMA-IR indexes shown in the opposite of order to IGI, as largest the number of 47.5 has found in pre-diabetes group, followed by a 16.8 in T2DM, 10.3 in obese. The control group had smallest number of 8.43. The results of HOMA-IR well associated with the postprandial glucose disappearance and beta cell function in each group.

\begin{tabular}{|l|l|l|}
\hline \multirow{2}{*}{ Group } & \multicolumn{2}{|l|}{ Parameters } \\
\cline { 2 - 3 } & IGI & HOMA-IR \\
\hline T2DM & 0.78 & 16.8 \\
\hline Pre diabetes & 0.82 & 47.5 \\
\hline Obese & 1.31 & 10.3 \\
\hline Control & 5.67 & 8.43 \\
\hline
\end{tabular}

Table 3: Values of IGI and HOMA-IR Data were presented as Mean.

\section{Discussion}

MMTT, OGTT, IVGTT, Arginine Stimulation Tests and hyperglycemic clamp are common methods have been used to assess insulin sensitivity and pancreatic beta cell function. The MMTT is physiological highly relevant mimicking oral challenges routinely encountered daily; as well as the full incretin hormone effect is able to be tested following the oral ingestion of nutrients [29]. We therefore conducted a MMTT in our animal models to assess glucose, insulin and glucagon although we have not assess other incretin hormones in current investigation.

The current study was undertaken to characterize the response to a MMTT in Cynomolgus monkeys with diet-induced metabolic derangements with focus on glucose, insulin and glucagon responses. The monkeys exhibited various degrees of insulin resistance as observed in human subjects according to the $\mathrm{HbA} 1 \mathrm{C} \%$ and glucose characteristics (i.e., either T2DM, pre-diabetes, obese or controls).

Control group obtained the smallest HOMA-IR and biggest IGI which suggests control monkeys are more insulin sensitive than other groups, and have the normal beta cell function which shown with rapidly secreted the adequately efficient insulin in response to postprandial glucose appearance and promotes glucose uptake in more insulin sensitive peripheral tissues to accelerate postprandial glucose disappearance. The glucagon secretion in control during the MMTT also showed as expected as normal physiology which the moderate elevated fasting glucagon concentration stimulated the gluconeogenesis to increase the hepatic glucose production to maintaining the euglycemic circulating range. And glucagon secretion has then suppressed when insulin and incretins hormone secretions dominated in postprandial phase until the glucose back to basal level. The insulin and glucagon actions in control group during MMTT are more resemble to normal physiological condition in healthy human [1]

In contrast, a bigger HOMA-IR and a smallest IGI indexes obtained in T2DM group suggesting of the monkeys of T2DM are more insulin resistance and had dysfunctional pancreatic beta cell. Fasting hyperglycemia and the greatest $\mathrm{AUC}_{0-240}$ min of postprandial glucose reflected a very slow rate of postprandial glucose disappearance caused by inadequately insulin secretion and a reduction in glucose uptake by insulin resistance peripheral tissue. The insulin secretion had delayed in response to postprandial glucose appearance and shaped with a small portion of preformed insulin in first phase and big portion of synthesized insulin in second phase appeared the dysfunctional beta 
Citation: Zhang C, Zhang L, Ding S, Fang Y, Sparre-Ulrich AH, et al. (2018) Postprandial Insulin and Glucagon Secretions during a Mixed-Meal Tolerance Test in Dietary Induced Metabolic Syndrome Cynomolgus Monkeys. J Vet Sci Technol 9: 550. doi: $10.4172 / 2157-7579.1000550$

Page 6 of 7

cells are unable to provide adequately insulin to help remove the postprandial glucose flux either mediate validate insulin signaling pathway for glucose utilization. This is very like T2DM human associated with insulin resistance and defective insulin secretion [30-32]. It is also known that T2DM human is associated with elevated levels of glucagon $[6,33,34]$ and defective suppression of glucagon secretion [33-36]. In our MMTT, the failure of glucagon inhibition by insulin in T2DM monkeys has been observed which glucagon secretion has increased an average $60 \%$ of fasting concentration over the postprandial time period. Our data is resembled to human.

The pre-diabetes group exhibited a similarity of insulin resistance to T2DM. It had a moderate elevated fast plasma glucose and small IGI, but the remarkable fasting hyperinsulinemia resulted in biggest HOMA-IR index than all other groups. The hyperinsulinemia is an adaptive mechanism that enables the maintenance of normoglycemia in the presence of insulin resistance [3]. The postprandial insulin secretion exerts similar as T2DM, a delayed secretion increasing occurred, but had an early started second phase for synthesized insulin that helped glucose flux and back to baseline. It has been documented by many clinical studies that association between hyperinsulinemia and T2DM, or insulin resistance indicated facilitated beta cell compensational efforts takes place to promoting insulin secretion and biosynthesis and beta cell growth to meet insulin demanding from excess glucose. The characterization of compensational hyperinsulinemia with pre-diabetes monkeys indicates the progression to overt T2DM; it resembled insulin resistance and pre-diabetes in human. We also observed that glucagon level in pre-diabetes accompanied with hyperinsulinemia was highest fasting level than others yet has elevated through most postprandial period of MMTT. Obesity is one of the fundamental factors underlying the current epidemic of T2DM [37-39].

From our data, the obese group had a mild high HOMA-IR than control group and moderate high IGI than T2DM and pre-diabetes groups. The slow postprandial glucose disappears with a slight increasing at 240 minutes, reflect the insulin resistance in peripheral tissue reduced the glucose uptake and utilize. Insulin secretion in response to glucose increase in post-meal period exerted as similar to the pre-diabetes. The glucagon suppression in response to MMTT is also diminished in obese monkeys. The increased postprandial level of glucagon, together with moderately elevated fast plasma insulin and postprandial insulin level are tightly coupled to a reduction of insulin sensitivity in the early stages of glucose deregulation [40]. All the data indicated that obesity is the beginning of pre-diabetes and T2DM.

The MMTT is a physiological relevant stimulus that mimics oral daily meal challenges. We conducted this MMTT in Cynomolgus monkeys to assess glucose, insulin and glucagon responses, and generally our findings are in alignment with human data. But our investigations still have some potential limitations. The first is the number of animals, which was limited due to time (development of the diet-induced changes) and costs. Eighteen monkeys were used and for analyses with high variance such as the glucagon measurements, the power to detect clinically relevant minor differences may not have been sufficient. Another potential limitation is lack of incretion data, which may underlay some of the changes in insulin, glucagon and glucose that were detected. Changes in hormones such as glucagonlike peptides 1 (GLP-1) and glucose-dependent insulin-tropic polypeptide (GIP) are clearly needed to be investigated in a NHP model.

\section{Conclusion}

In summary, although the number of subjects studied in this investigation was small, and it lacked with data of more incretins though, we believe it confirmed that the postprandial insulin, glucagon and glucose levels in different metabolic syndrome group respond differently to MMTT and the data from this investigation truly reflect the insulin sensitivity and beta cell function for the monkeys in each classified group and different groups response characteristics are very similar to human $[9,12,41,42]$. It is well demonstrated that cynomolgus monkeys are a good model to study metabolic syndrome and have translational value to human disease investigation.

\section{Acknowledgements}

We thank the WuXi Apptec., Ltd Lab Testing Division for their help and support, and Nianbo Lu, Lei Le, Tan $\mathrm{Xu}$, and Bing Xiao for technical assistance.

\section{References}

1. Stephen L, Aronoff MD, Berkowitz K, Shreiner B, Laura W, et al. (2004) Glucose Metabolism and Regulation: Beyond Insulin and Glucagon. Diabetes Spectrum 17: 3

2. Gromada J, Franklin I, Wollheim CB (2007) Alpha-cells of the endocrine pancreas: 35 years of research but the enigma remains. Endocr Rev 28: 84-116.

3. Faerch K, Vistisen D, Pacini G, Torekov SS, Johansen NB, et al. (2016) Insulin Resistance Is Accompanied by Increased Fasting Glucagon and Delayed Glucagon Suppression in Individuals With Normal and Impaired Glucose Regulation. Diabetes 65: 3473-3481.

4. Godoy-Matos AF (2014) The role of glucagon on type 2 diabetes at a Glance. Diabetol Metabol Syndr 6: 91.

5. Basu A, Alzaid A, Dinneen S, Caumo A, Cobelli C, et al. (1996) Effects of a change in the pattern of insulin delivery on carbohydrate tolerance in diabetic and nondiabetic humans in the presence of differing degrees of insulin resistance. J Clin Invest 97: 2351-2361.

6. Butler PC, Rizza RA (1991) Contribution to postprandial hyperglycemia and effect on initial splanchnic glucose clearance of hepatic glucose cycling in glucose-intolerant or NIDDM patients. Diabetes 40: 73-81.

7. Mitrakou A, Kelley D, Veneman T, Jenssen T, Pangburn T, et al. (1990) Contribution of abnormal muscle and liver glucose metabolism to postprandial hyperglycemia in NIDDM. Diabetes 39: 1381-1390.

8. Beltran-Sanchez H, Harhay MO, Harhay MM, McElligott S (2013) Prevalence and trends of metabolic syndrome in the adult U.S. population, 1999-2010. J Am Coll Cardiol 62: 697-703.

9. Haffner SM, Miettinen H, Gaskill SP, Stern MP (1996) Decreased insulin action and insulin secretion predict the development of impaired glucose tolerance. Diabetologia 39: 1201-1207.

10. Tripathy D, Carlsson M, Almgren P, Isomaa B, Taskinen MR, et al. (2000) Insulin secretion and insulin sensitivity in relation to glucose tolerance: lessons from the Botnia Study. Diabetes 49: 975-980.

11. Cavallo-Perin P, Bruno A, Scaglione L, Gruden G, Cassader M, et al. (1993) Feedback inhibition of insulin and glucagon secretion by insulin is altered in abdominal obesity with normal or impaired glucose tolerance. Acta Diabetol 30: 154-158.

12. Hamaguchi T, Fukushima M, Uehara M, Wada S, Shirotani T, et al. (1991) Abnormal glucagon response to arginine and its normalization on obese hyperinsulinaemic patients with glucose intolerance: importance of insulin action on pancreatic alpha cells. Diabetologia 34: 801-806.

13. Berrish TS, Hetherington CS, Alberti KGMM, Walker M (1995) Peripheral and hepatic insulin sensitivity in subjects with impaired glucose tolerance. Diabetologia 38: 699-704. 
Citation: Zhang C, Zhang L, Ding S, Fang Y, Sparre-Ulrich AH, et al. (2018) Postprandial Insulin and Glucagon Secretions during a Mixed-Meal Tolerance Test in Dietary Induced Metabolic Syndrome Cynomolgus Monkeys. J Vet Sci Technol 9: 550. doi: $10.4172 / 2157-7579.1000550$

Page 7 of 7

14. Shah P, Basu A, Basu R, Rizza R (1999) Impact of lack of suppression of glucagon on glucose tolerance in humans. Am J Physiol 277: E283-290.

15. Dinneen S, Alzaid A, Turk D, Rizza R (1995) Failure of glucagon suppression contributes to postprandial hyperglycaemia in IDDM. Diabetologia 38: 337-343.

16. Borghi VC, Wajchenberg BL, Cesar FP (1984) Plasma glucagon suppressibility after oral glucose in obese subjects with normal and impaired glucose tolerance. Metabol 12: 1068-1075.

17. Ahren B, Larsson H (2001) Impaired glucose tolerance (IGT) is associated with reduced insulin-induced suppression of glucagon concentrations. Diabetologia 44: 1998-2003.

18. Mitrakou A, Kelley D, Mokan M, Veneman T, Pangburn T, et al. (1992) Role of reduced suppression of glucose production and diminished early insulin release in impaired glucose tolerance. N Engl J Med 326: 22-29.

19. Luppino FS, de Wit LM, Bouvy PF, Stijnen T, Cuijpers P, et al. (2010) Overweight, obesity, and depression: a systematic review and meta-analysis of longitudinal studies. Arch Gen Psychiatry 67: 220-229.

20. Nauck M, Stockmann F, Ebert R, Creutzfeldt W (1986) Reduced incretin effect in type 2 (non-insulin-dependent) diabetes. Diabetologia 29: 46-52.

21. Henkel E, Menschikowski M, Koehler C, Leonhardt W, Hanefeld M (2005) Impact of glucagon response on postprandial hyperglycemia in men with impaired glucose tolerance and type 2 diabetes mellitus. Metabol: Clinic Experiment 54: 1168-1173.

22. Wagner JD, Cline JM, Shadoan MK, Bullock BC, Rankin SE, et al. (2001) Naturally occurring and experimental diabetes in cynomolgus monkeys: A comparison of carbohydrate and lipid metabolism and islet pathology. Toxicol Pathol 29: 142-148.

23. Harwood HJ Jr., Listrani P, Wagner JD (2012) Nonhuman primates and other animal models in diabetes research. J Diabetes Sci Technol 6: 503-514.

24. Mubiru JN, Garcia-Forey M, Higgins PB, Hemmat P, Cavazos N, et al. (2011) A preliminary report on the feeding of cynomolgus monkeys (Macaca fascicularis) with a high sugar high fat diet for 33 weeks. J Med Primatol 40: 335-341.

25. Wang X, Wang B, Sun G, Wu J, Liu Y, et al. (2015) Dysglycemia and Dyslipidemia Models in Nonhuman Primates: Part I Model of Naturally Occurring Diabetes. J Diabetes Metab S13: 010.

26. Ding S, Zhang C, Zhang L, Fang Y, Zhang X, et al. (2017) Fructose-Fed Induced Metabolic Syndrome Model in Cynomolgus Monkeys. J Vet Sci Technol 8: 478 .

27. Goedecke JH, Dave JA, Levitt NS, Lambert EV, West S, et al. (2009) Insulin response in relation to insulin sensitivity: An Appropriate betacell response in black South African women. Diabetes Care 32: 860-865.
28. Singh B, Saxena A (2010) Surrogate markers of insulin resistance: A review. World J Diabetes 15: 36-47.

29. Cersosimo E, Herrera CS, Trautmann ME, Malloy J, Triplitt CL (2014) Assessment of Pancreatic beta-Cell Function: Review of Methods and Clinical Applications. Curr Diabetes Rev 10: 2-42.

30. Reaven GM, Hollenbeck CB, Chen YDI (1989) Relationship between glucose tolerance, insulin secretion, and insulin action in non-obese individuals with varying degrees of glucose tolerance. Diabetologia 32: 52-55.

31. DeFronzo RA, Bonadonna RC, Ferrannini E (1992) Pathogenesis of NIDDM: A balanced overview. Diabetes Care 15: 318-368.

32. Ahren B, Pacini G (2004) Importance of quantifying insulin secretion in relation to insulin sensitivity to accurately assess beta cell function in clinical studies. Eur J Endocrinol 150: 97-104.

33. Muller WA, Faloona GR, Aguilar-Parada E, Unger RH (1970) Abnormal a-cell function in diabetes-Response to carbohydrate and protein ingestion. N Engl J Med 283: 109-115.

34. Reaven GM, Chen YD, Golay A, Jaspan JB (1987) Documentation of hyper glucagonemia throughout the day in nonobese and obese patients with noninsulin-dependent diabetes mellitus. J Clin Endocrinol Metab 64: $106-110$.

35. Unger RH, Orci L (1981) Glucagon and the A cell: physiology and pathophysiology (First of two parts). N Engl J Med 304: 1518-1524.

36. Unger RH, Orci L (1981) Glucagon and the A cell: physiology and pathophysiology (part 2). N Engl J Med 304: 1575-1580.

37. Center for Disease Control and Prevention (CDC) (2011) National diabetes fact sheet.

38. World Health Organization (2010) Global status report on NCDs, chapter 1: Burden: mortality, morbidity and risk factors.

39. World Health Organization (2012) Diabetes fact sheet Sept 2012.

40. Ahren B (2006) Glucagon secretion in relation to insulin sensitivity in healthy subjects. Diabetologia 49: 117-122.

41. Hanefeld M, Koehler C, Fuecker K, Henkel E, Schaper F, et al. (2003) Insulin secretion and insulin sensitivity pattern is different in isolated impaired glucose tolerance and impaired fasting glucose: the risk factor in Impaired Glucose Tolerance for Atherosclerosis and Diabetes study. Diabetes Care 26: 868-874.

42. Abdul-Ghani M, DeFronzo RA (2009) Fasting Hyperglycemia Impairs Glucose-But Not Insulin-Mediated Suppression of Glucagon Secretion. J Clin Endocrinol Metabol 92: 1778-1784. 